\title{
KKN KEBENCANAAN: DESA TANGGUH BENCANA SEBAGAI UPAYA PEMULIHAN EKONOMI DAN KONDISI SOSIAL PASCA BANJIR BANDANG
}

\section{Rahmad Solling Hamid, Salju, Suharnitha, Pelandira, Nur Fadillah, Naina Lusi, Dwi Rahmatya Ruddin}

\author{
Fakultas Ekonomi dan Bisnis Universitas Muhammadiyah Palopo \\ rahmadshamid@umpalopo.ac.id
}

\begin{abstract}
The flash flood disaster in Maipi, Masamba, North Luwu Regency occurred on July 13, 2020, has caused various problems. The community's unpreparedness in dealing with flash floods disasters creates psychological stress (traumatic) and social and economic impacts. This community service aimed to help the community increase their knowledge, abilities, and independence in facing and overcoming disaster problems after flash floods. The method used is by conducting disaster mitigation training and agricultural extension agents. The benchmarks for this activity's success are, first, increasing knowledge about disasters and ways of dealing with them in community groups. Second, community groups' increased capacity regarding the optimization of land damaged by flash floods as a forum for the community to produce vegetables with economic value.
\end{abstract}

Keywords: disaster resilient village, psychosocial, and economy.

\begin{abstract}
Abstrak
Bencana banjir bandang di Desa Maipi Kecamatan Masamba Kabupaten Luwu Utara yang terjadi pada tanggal 13 bulan Juli Tahun 2020 telah memunculkan beragam problematika. Ketidaksiapan masyarakat dalam menghadapi bencana banjir bandang memunculkan tekanan psikologis (traumatis) serta dampak sosial dan ekonomi. Tujuan pengabdian ini adalah membantu masyarakat dalam meningkatkan pengetahuan, kemampuan, dan kemandirian dalam menghadapi dan menanggulangi masalah kebencanaan pasca terjadinya banjir bandang. Metode yang digunakan yaitu dengan melakukan pelatihan mitigasi bencana dan penyuluh pertanian. Tolak ukur keberhasilan kegiatan ini pertama, meningkatnya pengetahuan tentang kebencanaan dan cara penanggulangannya pada kelompok masyarakat. Kedua, meningkatnya kemampuan kelompok masyarakat tentang optimalisasi lahan yang rusak akibat banjir bandang sebagai wadah bagi masayarakat untuk menghasilkan tanaman sayur sayuran yang bernilai ekonomis.
\end{abstract}

Kata kunci: desa tangguh bencana, psikosial, dan ekonomi. 


\section{PENDAHULUAN}

Indonesia merupakan negara dengan kondisi wilayah tropis yang jika memasuki musim kemarau terjadi bencana kebakaran lahan maupun hutan, sementara jika memasuki musim penghujan bencana yang terjadi yaitu longsor karena erosi dan banjir. Bencana alam yang paling umum dialami sebagaian besar wilayah di Indonesia yaitu bencana banjir dan kebakaran hutan (Tenrigau \& Dahlan, 2020). Menurut Pahleviannur, M. R. (2019), bahwa secara geografis Indonesia terletak pada pertemuan tiga lempeng aktif, yaitu Indo-Australia, Eurasia, dan Pasifik, kondisi ini mengakibatkan Indonesia mempunyai tingkat kerawanan tinggi terhadap bencana geologis dan hidroklimatologis. Kondisi ini tentunya berdampak pada manusia dan lingkungan. Fenomena ini memberikan sinyal peringatan bahwa masyarakat memiliki kewajiban dalam menjaga kehidupan sosial dengan menjaga keserasian, keseimbangan, serta kelestarian fungsi dari lingkungan hidup (Ginting \& Wijayanti, 2019). Sejalan dengan Undang-Undang Nomor 24 tahun 2007 tentang penanggulangan bencana, yang memahas mengenai tanggung jawab serta kewajiban pemerintah serta masyarakat untuk bekerja sama dalam kesiapsiagaan penanggulangan bencana.

Menurut Nurjanah, dkk (2013:11) suatu kejadian dapat digeneralisasi sebagai bencana apabila memenuhi beberapa kriteria yaitu adanya peristiwa yang terjadi, peristiwa tersebut terjadi disebabkan faktor alam maupun faktor manusia, terjadi secara tiba-tiba, namun dapat juga terjadi secara perlahan-lahan ataupun bertahap, menimbulkan kerugian harta benda, sosial-ekonomi, kerusakan lingkungan, hilangnya jiwa manusia dan lain sebagainya; dan penanggulangannya berada di luar kemampuan masyarakat.

Tepat pada tanggal 13 bulan Juli Tahun 2020 bencana banjir bandang telah menimpa salah satu wilayah di Timur Indonesia. Tepatnya di Desa Maipi Kecamatan Masamba Kabupaten Luwu Utara. Desa Maipi merupakan salah satu Desa yang terletak di daerah pegunungan di Kecamatan Masamba Kabupaten Luwu Utara. Secara geografis Desa maipi berbatasan dengan Sebelah Utara Kecamatan rampi, Sebelah selatan desa Baloli, Sebelah timur Desa Sumillin, Sebelah Barat Desa Meli. Ditinjau dari potensi perangkat aparat Pemerintah Desa Maipi memiliki 10 perangkat Desa, 3 Kepala Dusun dan 5 kepala RT. Keberadaan Badan Permusyawaratan Desa (BPD) dan Lembaga Ketahanan masyarakat Desa (LKMD)/Lembaga Perberdayaan Masyarakat Desa (LPM) dengan peran dan Fungsi masing masing. Desa Maipi memiliki luas wilayah lebih kurang 234,25 Km2 terdiri atas 3 Dusun (Dusun Maipi, Lero dan Mappatuju). Keadaan iklim di Desa Maipi terdiri dari: Musim Hujan, kemarau dan musim pancaroba. Dimana musim hujan biasanya terjadi antara Bulan Januari s/d April, musim kemarau antara bulan Juli s/d November, sedangkan musim pancaroba antara bulan Mei s/d Juni. Sebagian besar masyarakat Desa Maipi bermata pencaharian pokok sebagai seorang petani dan buruh tani. Potensi sumber daya alam terutama perkebunan dan pertanian.

telah $\begin{gathered}\text { Bencana alam banjir bandang } \\ \text { menghadirkan }\end{gathered}$ problematika yang dihadapi oleh masyarakat Desa Maipi Kecamatan Masamba Kabupaten Luwu Utara. Kondisi ini tentunya berdampak langsung pada aspek sosial maupun 
aspek ekonomi. Adapun permasalahan yang dihadapi oleh masyarakat Desa Maipi Kecamatan Masamba Kabupaten Luwu Utara yaitu, pertama, kurangnya pemahaman dalam menghadapi bencana merupakan salah satu faktor utama yang dialami masyarakat saat ini. Kedua, menurunnya kondisi psikologis yang dialami oleh masyarakat pasca banjir bandang. Ketiga, dampak sosial dan ekonomi menjadi fokus utama pemulihan yang harus ditangani oleh masyarakat dan pemerintah.

\section{METODE}

Kegiatan pengabdian kepada masyarakat melalui program desa tangguh bencana sebagai upaya pemulihan ekonomi dilakukan di Desa Maipi Kecamatan Masamba Kabupaten Luwu Utara yaitu salah satu desa yang terdampak langsung bencana banjir bandang. Pemberdayaan masyarakat merupakan sebuah upaya yang dilakukan untuk meningkatkan kemampuan dan keterampilan masyarakat agar dapat mewujudkan kemandirian dan melepaskan diri dari belenggu kemiskinan serta keterbelakangan (Mughni, 2018); Raharjo, Shofwan, Kisworo, Ilyas, \& Lestari (2020). Pemberdayaan difokuskan pada kelompok masyarakat yaitu pemuda karang taruna, kelompok tani, dan kelompok anak.

Untuk mewujudkan tujuan yang diharapkan, maka perlu dilakukan beberapa kegiatan yang terprogram dan berkesinambungan. Langkah-langkah dalam pelaksanaan program ini terdiri dari perencanaan, pelaksanaan dan evaluasi. Perencanaan diawali dengan persiapan tema dan tempat awal kegiatan KKN, pelaksanaan survey lapangan dan pencarian data terhadap tempat dan tema dengan melakukan koordinasi terhadap pihak terkait di lokasi yang akan dijadikan objek kajian. Hal ini dilaksanakan agar sasaran kegiatan tercapai dan membawa manfaat bagi pihak yang terlibat maupun pemerintah daerah setempat. Selanjutnya menentukan rancangan program kerja, menentukan tim dan pembagian tugas sesuai bidang studi, serta pelaksanaan pembekalan dan gladiresik. Pelaksanaan program mengikuti jadwal yang telah ditetapkan oleh LPPM Universitas Muhammadiyah Palopo dengan catatan proses identifikasi telah diselesaikan. Kegiatan- kegiatan pada tahapan ini difokuskan pada implementasi program dengan mempergunakan berbagai metode komunikasi. Seperti Penyuluhan Pertanian, Psikososial, Mitigasi Bencana. Tahapan Evaluasi ini diisi dengan berbagai kegiatan monitoring dan evaluasi berbagai program kegiatan yang telah dicanangkan. Hasil dari proses ini adalah beberapa data dan informasi perkembangan implementasi program KKN yang dilakukan secara periodik selama KKN berlangsung dan pasca program KKN dilaksanakan.

Program pasca KKN yang rencananya akan dilakukan adalah monitoring terhadap serangkaian kegiatan pelatihan. Harapannya, kelompok masyarakat dapat mandiri, bertambahnya pengetahuan tentang desa tanggap bencana, serta memiliki jiwa social preneur. Sehingga mampu. Selain itu, proses monitoring berfungsi sebagai pemantauan dan pemeliharaan kondisi infrastruktur, baik yang telah dikelola maupun yang direncanakan. Selain monitoring, perlu diadakan evaluasi secara menyeluruh dan periodik terhadap program yang telah dibuat dan diaplikasikan selama KKN. Apakah program tersebut terbukti memberikan efek positif dalam membantu masyarakat Desa Maipi atau sebaliknya. Apabila hasil dari kegiatan ini bernilai 
positif, maka sebaiknya program ini dijadikan sebagai program lanjutan untuk kegiatan KKN pada periode selanjutnya. Namun, jika hasil yang diperoleh sebaliknya maka hendaknya dilakukan tindakan perbaikan..

\section{HASIL DAN PEMBAHASAN}

Mengingat urgensi peran perguruan tinggi dalam membangun masyarakat sadar bencana. Dosen dan mahasiswa Universitas Muhammadiyah Palopo telah melaksanakan salah satu bentuk tri dharma perguruan tinggi yaitu kegiatan pengabdian kepada masyarakat. Kegiatan ini dilaksanakan dalam kurun waktu selama 30 hari dimulai pada tanggal 22 September sampai dengan 22 Oktober 2020. Bertempat di Desa Maipi Kecamatan Masamba Kabupaten Luwu Utara yang merupakan salah satu desa yang terkena dampak banjir bandang. Dengan mengusung tema Kebencanaan terdapat tiga program utama kegiatan pengabdian telah berhasil di realisasikan, diantaranya:

\section{Psikososial}

Kegiatan psikososial bertujuan untuk mengembalikan individu atau keluarga serta kelompok yang ada di Desa Maipi pasca kejadian banjir bandang, sehingga dapat lebih kuat secara individu maupun kolektif. Selain itu, kegiatan ini bertujuan untuk membentuk masyarakat yang tangguh dalam menghadapi masalah serta berdaya dan produktif dalam menjalani hidupnya. Pemulihan psikososial merupakan kegiatan yang bertujuan untuk memperbaiki interaksi sosial antara individu dengan individu lainnya dalam suatu kelompok masyarakat, sehingga dapat kembali berperan aktif untuk mengikuti kegiatan kemasyarakatan (Sakinah, 2010).
Psikososial dikemas dalam bentuk sekolah ceria dan pengajian bersama dengan kelompok ibu-ibu majelis ta'lim. Adapun kegiatan ini tetap memperhatikan protokol kesehatan.

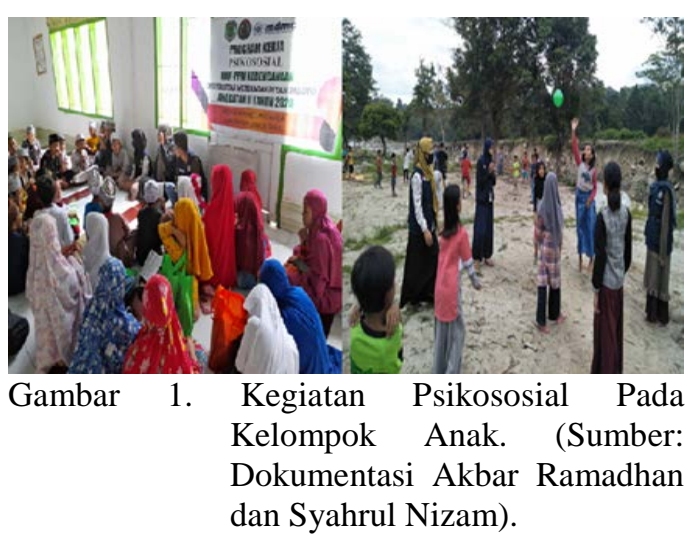

\section{Penyuluhan Pertanian Pasca Banjir}

Tujuan dari kegiatan pengabdian ini adalah memberikan stimulus kepada masyrakat khususnya kelompok tani dan ibu-ibu rumah tangga bagaimana memulai kembali bercocok tanam pasca banjir. Penyuluh pertanian mampu berperan dalam membantu petani agar dapat menolong dirinya dalam mengatasi permasalahan yang dihadapinya dengan baik serta memuaskan sehingga dapat meningkatkan derajat kehidupannya (Sadono, 2008). Menurut Hermanto, Ismillayli, Zakirrahman, Jannaturrayyan, \& Nartiadi (2020), bahwa kegiatan pengabdian integrasi perkebunan dalam mewujudkan rumah pangan lestari terbukti mampu menambah pengetahuan dan keterampilan masyarakat tentang teknik budidaya hasil pertanian seperti budidaya sayur dan pembuatan pupuk kompos. Adapun pada kegiatan ini difokuskan pada tanaman jangka pendek, seperti tanaman, sayur, lombok, terong dan beberapa tanaman jangka pendek lainnya. Sehingga masyarakat mampu produktif baik dalam memenuhi 
kebutuhan mereka sehari-hari serta untuk menambah penghasilan.

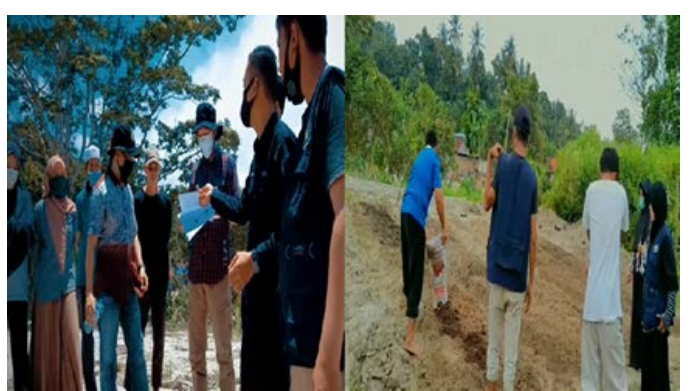

Gambar 2. Kegiatan Penyuluh Pertanian (Sumber: Dokumentasi Akbar Ramadhan dan Syahrul Nizam).

\section{Mitigasi Bencana}

Pada kegiatan ini Mahasiswa dan dosen berkolaborasi dengan MDMC Luwu Utara. Tujuan dari kegiatan pengabdian ini yaitu untuk membangun kesadaran masyarakat agar tanggap pada bencana. Desa Tanggap Bencana merupakan salah satu perioritas kegiatan yang akan dilakukan secara berkesinambungan melalui kerjasama MDMC Luwu Utara. Menurut Rahman (2015), bahwa upaya yang dapat dilakukan dalam meningkatkan efektifitas mitigasi bencana adalah dengan pembentukan masyarakat tanggung serta desa tangguh bencana. Mitigasi bencana mencakup baik perencanaan dan pelaksanaan berbagai tindakan dalam mengurangi resiko dampak dari suatu bencana yang dilakukan sebelum bencana itu terjadi, termasuk kesiapan dan tindakan - tindakan pengurangan resiko jangka panjang (Suwaryo \& Yuwono, 2017). Selanjutnya dosen, mahasiswa dan dibantu oleh IT Universitas Muhammadiyah mampu menciptakan alat sensor ketinggian debit air. Alat ini mampu berfungsi sebagai alat yang memberikan informasi yang tepat akurat. Alat ini dikoneksikan dengan bunyi serine dan notifikasi melalui sms untuk memberikan informasi tentang ketinggian air.

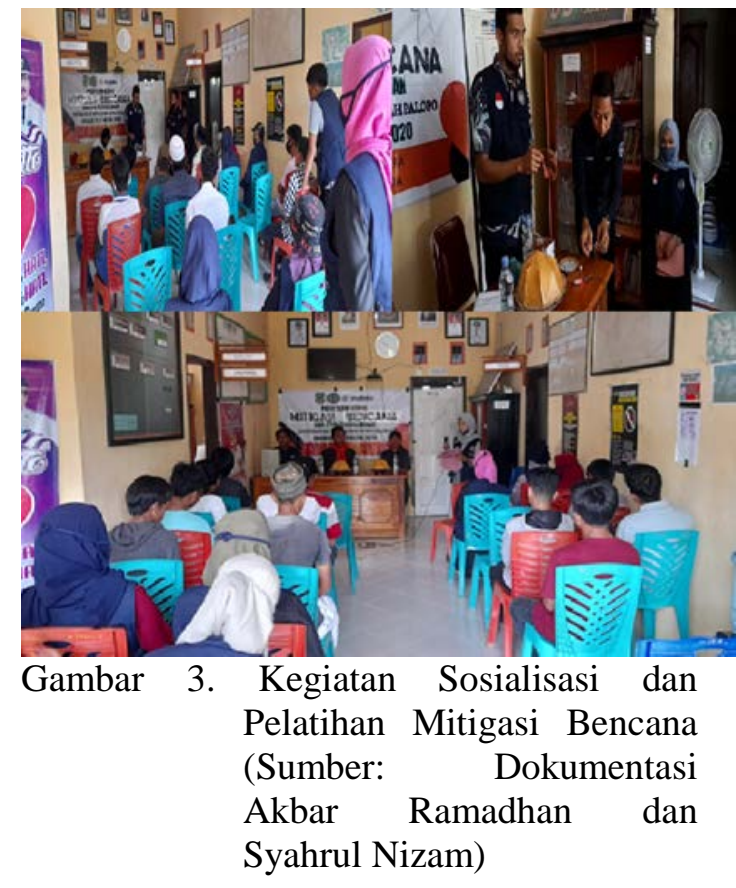

Berdasarkan hasil wawancara dengan perwakilan aparat desa dan tokoh masyarakat di Desa Maipi bahwa pada umumnya keseluruhan program kerja kegiatan pengabdian kepada masyarakat yang telah terealisasi dapat diterima dengan baik oleh masyarakat. Lebih lanjut, masyarakat memperoleh beragam manfaat dari kegiatan-kegiatan yang telah dilakukan oleh mahasiswa. Adanya edukasi terkait dengan program Desa Tagana (Desa Tanggap Bencana) merupakan salah satu kegiatan yang mengedukasi masyarakat khususnya pemuda tentang kesiap siagaan dalam mengahdapi bencana yang sewaktu waktu bisa saja terjadi. Selain itu, program penyuluh pertanian pasca banjir dianggap mampu memberikan stimulus kepada masyarakat pada umumnya dan kelompok ibu-ibu rumah tangga serta kelompok tani khususnya. Untuk kegiatan psikososial dianggap mampu menciptakan kekuatan baru baik secara individu dan kelompok. Secara umum melalui serangkaian kegiatan 
pengabdian oleh mahasiswa dan dosen Universitas Muhammadiyah Palopo, masyarakat telah memiliki sumber kekuatan dan motivasi baru untuk memulai kembali proses kehidupan pasca banjir bandang.

\section{SIMPULAN}

Kegiatan KKN PPM

Kebencanaa yang merupakan bentuk dari pengabdian kepada masyarakat yang telah dilaksanakan di Desa Maipi Kecamatan Masamba Kabupaten Luwu Utara dengan berfokus pada kelompok masyarakat telah berjalan dengan baik dan lancar. Dapat disimpulkan bahwa serangakain pelatihan yang telah dilakukan yaitu mitigasi bencana, penyuluh pertanian, dan psikososial berbasis teori dan praktik lapang yang diberikan mampu meningkatkan informasi pengetahuan dan keterampilan kelompok masyarakat. Kondisi psikologis masyarakat khusunya kelompok anak setelah dilakukannya kegiatan psikosisial berangsur membaik. Hal ini dibuktikan dengan tingginya antusiasme mereka untuk terus mengikuti serangkaian kegiatan yang sifatnya terjadwal. Melalui kegiatan pelatihan penyuluh pertanian ternyata mampu memberikan stimulus tentang bagaimana memulai kembali mengolah lahan yang telah rusak akibat banjir bandang. Masyarakat juga sudah mampu menghasilkan tanaman jangka pendek seperti sayur sayuran, tanaman ubi, jagung yang dapat dikonsumsi dan bernilai ekonomis khususnya pada peningkatan pendapatan masyarakat.

\section{UCAPAN TERIMA KASIH}

Penulis mengucapkan terima kasih kepada Lembaga Penelitian dan Pengabdian Masyarakat (LPPM)
Universitas Muhammadiyah Palopo yang telah mendukung penuh kegiatan pengabdian KKN Kebencanaan tahun 2020.

\section{DAFTAR PUSTAKA}

Anonim. (2007). UU Nomor 24 tahun 2007 Tentang Penanggulangan Bencana.

Ginting, A. H., \& Wijayanti, T. D. (2019). Pemberdayaan Masyarakat Melalui Program Desa Tangguh Bencana di Kabupaten Kutai Kartanegara. TRANSFORMASI: Jurnal Manajemen Pemerintahan, 11(2), 42-57. Retrieved from http://ejournal.ipdn.ac.id/JTP/a rticle/view/695

Hermanto, D., Ismillayli, N., Zakirrahman, $\quad$ M., Jannaturrayyan, S., \& Nartiadi, L. A. (2020). Integrasi Perkebunan, Perikanan, dan Peternakan untuk Mewujudkan Rumah Pangan Lestari di Desa Banyu Urip, Lombok Tengah. Jurnal Pengabdian Pada Masyarakat, 5(2), 409-414.

MUGHNI, D. I. (2018). STRATEGI PENGEMBANGAN

KEMANDIRIAN EKONOMI SANTRI (Studi Kasus di Pondok Pesantren El-Bayan Bendasari Majenang Cilacap Jawa Tengah). Skripsi. Program Studi Ekonomi Syariah Fakultas Ekonomi Dan Bisnis Islam. Institut Agama Islam Negeri Purwokerto. Retrieved from http://repository.iainpurwokert o.ac.id/3743/

Pahleviannur, M. R. (2019). Edukasi Sadar Bencana Melalui Sosialisasi Kebencanaan Sebagai Upaya Peningkatan 
Rahmad Solling Hamid, dkk. Kkn Kebencanaan: Desa Tangguh Bencana Sebagai...

Pengetahuan Siswa Terhadap Mitigasi Bencana. Jurnal Pendidikan Ilmu Sosial, 29(1), 49-55.

Raharjo, T., Shofwan, I., Kisworo, B., Ilyas, I., \& Lestari, J. (2020). Penyuluhan Pertanian Budidaya Ubi Jalar Organik Berbasis Sociopreneurship. JURNAL PANJAR: Pengabdian Bidang Pembelajaran, 2(2), 35-41.

Rahman, A. Z. (2015). Kajian Mitigasi Bencana Tanah Longsor di Kabupaten Banjarnegara. GEMA PUBLICA: Jurnal Manajemen dan Kebijakan Publik, 1(1), 1-14.

Sadono, D. (2008). Pemberdayaan petani: paradigma baru penyuluhan pertanian di Indonesia. Jurnal penyuluhan, 4(1). 65-74.

Sakinah, A. A. (2010). Pemulihan Psikososial Pasca Gempa Bumi 27 Mei 2006 Melalui Program Psikososial Support Program (Psp) Palang Merah Indonesia (Pmi) Cabang Bantul (Studi Kasus Di Dusun Pelemadu, Sriharjo, Imogiri, Bantul, Yogyakarta). Skripsi. Universitas Islam Negri Sunan Kalijaga. Retrieved from http://digilib.uinsuka.ac.id/5076/1/BAB I,IV, DAFTAR PUSTAKA.pdf

Suwaryo, P. A. W., \& Yuwono, P. (2017). Faktor-faktor yang mempengaruhi tingkat pengetahuan masyarakat dalam mitigasi bencana alam tanah longsor. URECOL, 305-314.
Tenrigau, A. M., \& Dahlan, H. (2020). Model Governansi Manajemen Penanganan Korban Banjir: Studi Siri'na Pesse Metodologi Di Luwu Utara. JEMMA (Journal of Economic, Management and Accounting), 3(2), 181-193. 